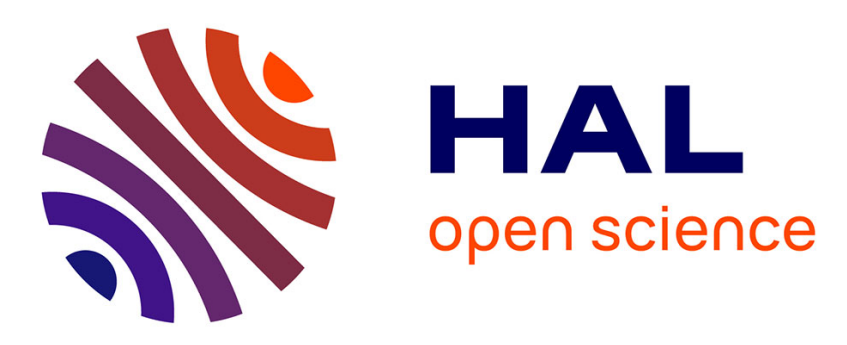

\title{
Effect of simultaneous lip-tube and auditory feedback perturbations
}

\author{
Lambert Beaudry, Pascal Perrier, Lucie Ménard
}

\section{To cite this version:}

Lambert Beaudry, Pascal Perrier, Lucie Ménard. Effect of simultaneous lip-tube and auditory feedback perturbations. 177th Meeting of the Acoustical Society of America, May 2019, Louisville, Kentucky, United States. , The Journal of The Acoustical Society of America, Vol. $145 \bullet$ No. $3 \bullet$ Pt. 2 of 2 , 2019. hal-02407067

\section{HAL Id: hal-02407067 https://hal.science/hal-02407067}

Submitted on 12 Dec 2019

HAL is a multi-disciplinary open access archive for the deposit and dissemination of scientific research documents, whether they are published or not. The documents may come from teaching and research institutions in France or abroad, or from public or private research centers.
L'archive ouverte pluridisciplinaire HAL, est destinée au dépôt et à la diffusion de documents scientifiques de niveau recherche, publiés ou non, émanant des établissements d'enseignement et de recherche français ou étrangers, des laboratoires publics ou privés. 


\section{Laboratoire}

de phonétique

\section{UQĀM}

\section{Effects of simultaneous lip-tube} and auditory feedback perturbations

Lambert Beaudry ${ }^{1}$, Pascal Perrier ${ }^{2}$ \& Lucie Ménard ${ }^{1}$

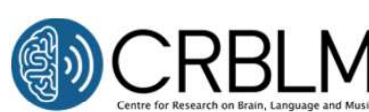

UQĀM | CRLEC

Centre de recherche sur le langage,
l'esprit et le cerveau

FACULTÉ DES SCIENCES HUMAINES
Université du Québec à Montréal

${ }^{1}$ Laboratoire de phonétique, Université du Québec à Montréal, Canada; ${ }^{2}$ GIPSA-Lab, Grenoble, France

lambert.beaudry@gmail.com; menard.lucie@uqam.ca; Pascal.Perrier@gipsa-lab.grenoble-inp.fr

\section{BACKGROUND}

-Speech production involves feedback and feedforward control mechanisms (Perkell, 2012)

-Somatosensory (SS) and auditory (AUD) aspects of speech can be perturbed to study speech production (Savariaux et al., 1995, 1999; Ménard et al. 2016)

-Previous experiments with adult French speakers producing the vowel $/ \mathrm{u} /$ with a perturbation of the lips using a lip-tube showed that they were able to compensate in part by moving the tongue towards the velo-pharyngeal region, using auditory feedback (Savariaux et al., 1995,1999; Ménard et al., 2016).

- The relative importance of auditory and somatosensory feedback on compensatory strategies to a lip-tube perturbation is not clear.

\section{OBJECTIVE}

- This study aimed to evaluate the compensatory strategies of adult speakers of Quebec French in producing the vowel / $u$ / with a perturbation of the lips using a lip-tube, with and without natural or perturbed auditory feedback.

\section{Participants}

-10 males and 10 females

-18 to 35 years old $($ mean age $=25.3$ )

-Native speakers of Quebec French

-No known pathology related to audition, language, or attention

Task

-To produce 6 blocks of $20 / u$ / tokens.

-60 tokens were produced while the speaker

had a plastic lip-tube between the lips that

was designed to increase lip area, thus F1 and

F2 values.

-20 of the 60 tokens were also produced with simultaneous real-time modified auditory feedback designed to decrease $\mathrm{F} 1$ and $\mathrm{F} 2$ (Cai et al., 2008).

METHOD

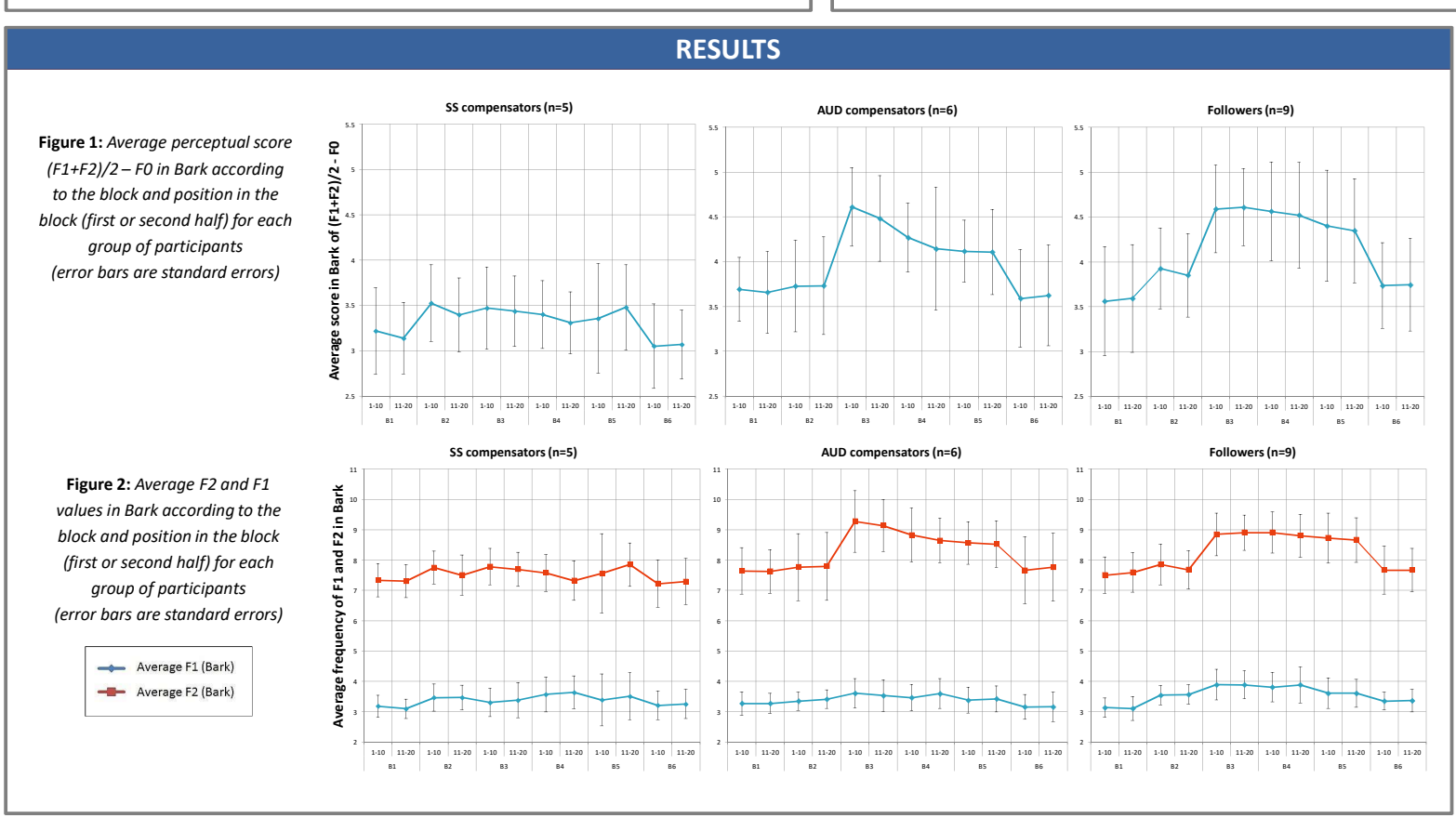

\section{Experimental setup}

-The participant was seated, wearing headphones and instructed not to talk after the experiment had started.

-A microphone was held by the experimenter

-The participant was instructed to wait for a green signal on the screen and then produce the vowel /u/ 20 times, as clearly as possible.

A lip-tube $(2.0 \mathrm{~cm}$ long by $2.5 \mathrm{~cm}$ wide) was placed between the lips of the participan before the $3^{\text {rd }}$ block of the experiment and left there until the end of the $5^{\text {th }}$ block.

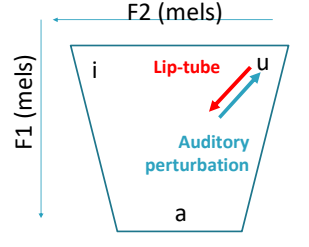
in front of the participant.

Data analysis

$-F 0, F 1$, and F2 values were extracted at rowel midpoints for the $120 / \mathrm{u} /$ tokens produced by each participant.

The participants were divided into 3 groups based on their compensation strategies:

SS compensators: those who started to compensate in block 3 (lip-tube, perturbed auditory feedback) $(\mathbf{n}=5$ )

- AUD compensators: those who minimally compensate in block 3 (lip-tube) but did so in

block 4 (no AUD feedback) $(n=6)$

Followers: those who followed the liptube perturbation and did not compensate with AUD feedback $(\mathbf{n}=\mathbf{9})$;

-LME models were built using $R$.

\begin{tabular}{|c|c|c|c|c|c|}
\hline Block 1 & Block 2 & Block 3 & Block 4 & Block 5 & Block 6 \\
\hline No lip-tube & No lip-tube & Lip-tube & Lip-tube & Lip-tube & No lip-tube \\
\hline $\begin{array}{l}\text { Natural auditory } \\
\text { feedback }\end{array}$ & No auditory feedback & $\begin{array}{l}\text { Auditory feedback } \\
\text { perturbation }\end{array}$ & No auditory feedback & $\begin{array}{l}\text { Natural auditory } \\
\text { feedback }\end{array}$ & $\begin{array}{l}\text { Natural auditor } \\
\text { feedback }\end{array}$ \\
\hline
\end{tabular}

\section{DISCUSSION}

-There appear to be three distinct responses to SS (lip) perturbation:

1. compensation for SS perturbation when no auditory consequences are heard (SS)

2. no compensation for SS perturbation when AUD feedback is corrected (AUD)

3. no compensation

- The SS compensators' $\mathrm{F} 2$ values during block 3 were not higher than values from blocks 1 and 2 suggesting the immediate minimization of somatosensory feedback erro (primacy of somatosensory feedback over auditory feedback).

- The AUD compensators' F2 values increased in block 3 and began gradually decreasing before access to natural auditory feedback was restored, suggesting that both auditory and somatosensory feedback were integrated in the compensation.

\begin{tabular}{|c|}
\hline REFERENCES \\
\hline 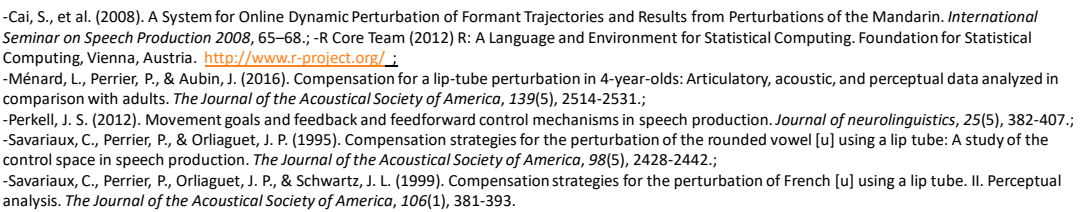 \\
\hline
\end{tabular}

